\title{
Preclinical Atherosclerosis and Other Determinants of Venous Thromboembolism in Patients With Thrombophilias
}

\author{
O. AUZKÝ ${ }^{1}$, L. PAGÁČOVÁ ${ }^{2}$, T. ŠEJDA ${ }^{3}$, J. PIŤHA ${ }^{1,4}$
}

${ }^{1}$ Center for Cardiovascular Research, Institute for Clinical and Experimental Medicine, Prague, Czech Republic, ${ }^{2}$ Department of Hematology, Institute for Clinical and Experimental Medicine, Prague, Czech Republic, ${ }^{3}$ First Department of Internal Medicine, Thomayer Faculty Hospital, Prague, Czech Republic, ${ }^{4}$ Laboratory for Atherosclerosis Research, Institute for Clinical and Experimental Medicine, Prague, Czech Republic

Received August 7, 2009

Accepted January 15, 2010

On-line April 20, 2010

\section{Summary}

At present, the supposed association between venous thromboembolism and atherosclerosis has yet to be proven. However, no data are available from patients with thrombophilias. We evaluated the association between preclinical atherosclerosis and prevalence of thromboembolic events in patients with thrombophilias. Presence of preclinical atherosclerosis in common carotid and femoral arteries measured by ultrasound was assessed by Belcaro score (based mainly on the presence of plaques) and by measurements of intima media thickness in the same location in 109 patients (43 men, mean age $41.5 \pm 13$ years) with established thrombophilias. Other parameters under the study were age, presence of traditional cardiovascular risk factors, anthropometric and clinical data including blood pressure measurements and medication. The differences between patients with $(n=47)$ and without $(n=62)$ thromboembolic events were assessed by paired t-test and chi square tests. In patients with a history of venous thromboembolism, body mass index and the prevalence of antihypertensive treatment (AT) were significantly higher than in patients without history of thromboembolism (BMI: $26.5 \pm 5.0$ vs. $24.4 \pm 3.7 \mathrm{~kg} / \mathrm{m}^{2} ; \mathrm{p}=0.04$, AT: $25.5 \%$ vs. $8.1 \%$; $=0.013$ ). No significant differences between groups were found regarding preclinical atherosclerosis. Overweight and hypertension, but not preclinical atherosclerosis, were more prevalent in patients with thrombophilias suffering from thromboembolism.

\section{Key words}

Preclinical atherosclerosis • Ultrasonography • Venous thromboembolism • Thrombophilia

\section{Corresponding author}

Ondřej Auzký, Center for Cardiovascular Research, Institute for Clinical and Experimental Medicine, Vídeňská 1952/8, 14021 Prague 4, Czech Republic. Fax: +0420 241271 574. E-mail: auzky@seznam.cz

\section{Introduction}

Venous thromboembolism (VTE) represents one of the most common cardiovascular diseases in developed countries (Gillum et al. 1987, Nordström et al. 1992). Among the most powerful risk factors for this clinical event are thrombophilias. However, not all patients with established diagnosis of thrombophilia develop VTE (Crowther and Kelton 2003). VTE is a potentially fatal condition, but anticoagulation therapy is not without risk. Therefore, the detection of other factors that may help to stratify patients at risk of development of VTE is of great importance. Among most recently discussed risk factors is atherosclerosis in its preclinical form, potentially responsible for the activation of coagulation cascade and activation of platelets.

Although atherosclerosis and VTE are traditionally viewed as separate conditions, they share common characteristics. The common feature of atherosclerosis and VTE is endothelial dysfunction (Migliacci et al. 2007) and both atherosclerosis and VTE share common risk factors such as age, obesity, increased waist circumference and metabolic syndrome (Ageno et 
al. 2006, Ageno et al. 2008). In addition, it has been found that thrombophilias, such as Leiden mutation of factor $\mathrm{V}$, prothrombin mutation and protein $\mathrm{C}$ and $\mathrm{S}$ deficiency, are risk factors not only for VTE but also for atherosclerosis (Rosendaal et al. 1997, Eitzman et al. 2005, Marchiori et al. 2007, Bank et al. 2004, Mahmoodi et al. 2008). Other proposed common risk factors for VTE and atherosclerosis include arterial hypertension, smoking, diabetes mellitus and dyslipidemia (Lowe 2008).

The hypothesis that VTE and atherosclerosis share common pathways is supported by recently published study in which the potent hypolipemic/ antiatherogenic drug - rosuvastatin - significantly reduced not only clinical complications of atherosclerosis but also symptomatic VTE (Glynn et al. 2009). Therefore, it could be possible that atherosclerosis besides local procoagulative action exerts systemic procoagulative activity that may contribute to thrombus formation in the distant vascular bed (Prandoni 2007).

However, other studies addressing the issue of the relation between atherosclerosis and VTE yielded controversial results. In a prospective case-control study of 299 unselected patients with deep vein thrombosis (DVT), more carotid plaques had been found in patients with unprovoked DVT compared to patients with DVT of known origin (Prandoni et al. 2003). In accordance with this finding, in a retrospective case-control study, more coronary calcifications were found in patients with unprovoked VTE compared to controls without VTE (Hong et al. 2005). In other studies, more cardiovascular events have been found in patients after VTE (Becattini et al. 2005, Bova et al. 2006, Sørensen et al. 2007). In contrast, two population-based studies did not reveal that atherosclerosis is predictive of VTE (van der Hagen et al. 2006, Reich et al. 2006).

It has not been studied so far if patients with thrombophilias and preclinical atherosclerosis are at a higher risk for VTE. We evaluated whether the presence of preclinical atherosclerosis in peripherally located arteries and other common cardiovascular risk factors are associated with VTE in patients with thrombophilias.

\section{Methods}

Participants of the study were patients with defined thrombophilias recruited through the department of hematology. The Ethics Committee of the Institute approved the study and all participants signed an informed consent.

All participants were interviewed about their medical history according to a standardized protocol. Medical history was focused on the type of thrombophilias confirmed by a hematologist. In addition, information about history of myocardial infarction, angina pectoris, transient ischemic attack, stroke, intermittent claudication, arterial revascularization, smoking, presence of diabetes mellitus, hypertension, dyslipidemia, cancer and current medication including hormonal therapy was obtained. Body height, weight, waist circumference and blood pressure were also measured according to a standardized protocol. Body mass index was calculated as weight in $\mathrm{kg}$ over squared height in meters.

For statistical analyses, patients with a history of regular smoking were defined as smokers, hypertension was defined as the use of antihypertensive drugs and/or systolic blood pressure above $140 \mathrm{mmHg}$ and/or diastolic blood pressure above $90 \mathrm{mmHg}$, diabetes mellitus was defined as self-reported regular use of diabetic diet and/or antidiabetic drugs, and dyslipidemia was defined as selfreported use of lipid-lowering drugs or knowledge of higher blood lipids, also reported by the patients.

Data regarding a history of VTE, localization of venous thrombosis, the cause of the VTE and use of anticoagulant treatment were obtained from the medical records of each subject. Provoked venous thrombosis was defined if it had occurred after the exposure to exogenous risk factors (immobilization including trauma or surgery, cancer, pregnancy and the use of oral steroids).

All subjects underwent bilateral ultrasound assessment of the carotid and femoral arteries by Toshiba APLIO 50 XV (Tochigi, Japan) ultrasound system with a 7.5-10 MHz linear array transducer. The carotid arteries were examined with the patient in the supine position and the neck rotated 45 degrees in the direction opposite the site being examined. The images of the common, internal and external carotid arteries were obtained at the end of diastole (onset of the $\mathrm{R}$ wave on the electrocardiogram). Subsequently, the femoral arteries were examined with the supine patient. The images of the common femoral arteries and their bifurcations were obtained at the end of diastole (onset of the $\mathrm{R}$ wave on the electrocardiogram). All arteries were scanned by transverse and longitudinal projection. The images were subsequently digitalized and read offline (using vPACS DS software, version 6.9.25, Czech Republic). Both the sonographer and the reader were blinded with regard to presence/absence of history 
of VTE and concomitant use of anticoagulant medications.

The presence of preclinical atherosclerosis was defined by semiquantitative classification - the Belcaro score - and by the intima-media thickness measurements. The classification was based on measurements obtained in common carotid arteries and their bifurcations and in common femoral arteries and their bifurcations. The classification by Belcaro et al. (1996) has been described elsewhere. This classification evaluates the degree of preclinical atherosclerosis based on ultrasound criteria:

Class I: normal - three ultrasonic layers (intimamedia, adventitia, and periadventitia) clearly separated, no disruption of lumen-intima interface for at least $3.0 \mathrm{~cm}$, and/or initial alterations (lumen-intima interface disruption at intervals of $<0.5 \mathrm{~cm}$ ).

Class II: intima-media granulation, granular echogenicity of deep, normally unechoic intimal-medial layer and/or increased intima-media thickness ( $>1 \mathrm{~mm})$.

Class III: plaque without hemodynamic disturbance, localized wall thickening and increased density involving all ultrasonic layers, intima-media thickness $>2 \mathrm{~mm}$.

Class IV: stenotic plaque, as in Class III, but with hemodynamic stenosis on duplex scanning (sample volume in the center of the lumen), indicating stenosis $>50 \%$.

The highest value of the Belcaro score found in the arterial system (either in carotid or in femoral arteries) in each subject was used for further analyses.

Digitized images in end-diastole were used to trace the media-adventitial and intima-lumen interfaces and for calculations of mean intima media thickness in arteries under study. A mean of four measurements in the far wall of a distal $(10 \mathrm{~mm})$ segment of both common carotid arteries (two in the right and two in the left common carotid artery) and both common femoral arteries (two in the right and two in the left femoral artery) was used as an outcome for statistical analyses. The mean intima-media thickness used for statistical analyses thus was the average of 8 measurements ( 4 from common carotid and 4 from common femoral arteries).

The variability of assessment of the highest value of the Belcaro score found in the arterial system (either in carotid or in femoral arteries) was assessed in 10 randomly chosen patients ( 5 men, 5 women; age 20-73 years) by two independent observers (O.A, and J.P.), who classified the Belcaro score in 1 week interval. The interobserver variability (assessed within 1 week interval) was
$2 \%$, with an intra-class correlation coefficient $=0.96$.

The study data are presented as percentages for categorical variables and means for continuous ones. Between groups comparison of continuous variables was calculated using paired t-test; for discrete variables, a chi square test was applied, for subgroups a Fisher exact test was used. Partial correlation analyses were performed to detect variables significantly associated with VTE status after stratifying for body mass index and hypertension.

\section{Results}

The primary study population consisted of 134 patients. Twenty-five subjects were subsequently considered as not being carriers of a thrombophilia. From those, sixteen patients had established diagnosis of isolated methylenetetrahydrofolate reductase mutations with or without hyperhomocysteinemia that were considered to be at low risk for VTE (Lijfering et al. 2007), and in nine subjects no laboratory defect consistent with a diagnosis of thrombophilia was confirmed. Data from resulting 109 patients (43 men, mean age $41.5 \pm 13$ years) were used for the final analysis. Forty seven $(43.1 \%)$ patients had a history of VTE, among them the VTE was regarded as unprovoked in 19 patients $(40.4 \%)$. Characteristics of the study subjects based on the two patients' groups divided according to the presence or absence of a history of VTE are presented in Tables 1 and in 2. There were more subjects with homozygous mutation of the factor $\mathrm{V}$ Leiden in the VTE group and more subjects with heterozygous mutation of the factor V Leiden in the non-VTE group. These differences were of borderline statistical significance, however, the overall prevalence of the factor $\mathrm{V}$ Leiden mutations was not different between the study groups $(\mathrm{p}=0.34)$. Among the study patients, six were treated with beta sympatholytics, nine with angiotensin converting enzyme inhibitors, three with angiotensin receptor blockers, eight with calcium channel blockers, one with diuretic (patient without history of VTE), and one with antihypertensive drug from other class.

The Belcaro score above I indicating the presence of preclinical atherosclerosis was found in $68.1 \%$ of patients with a history of VTE and in $59.7 \%$ of the patients without a history of VTE. After stratifying for body mass index and antihypertensive treatment, the trend to more prevalent preclinical atherosclerosis based on the Belcaro score in patients with the history of VTE was more pronounced, but did not reach statistical significance (Table 3). 
Table 1. Prevalence of thrombophilias within the study population.

\begin{tabular}{llll}
\hline & $\begin{array}{l}\text { History of venous } \\
\text { thromboembolism } \\
\mathbf{n = 4 7}\end{array}$ & $\begin{array}{l}\text { No history of venous } \\
\text { thromboembolism } \\
\mathbf{n}=\mathbf{6 2}\end{array}$ & $\mathbf{p}\left(\chi^{\mathbf{2}}\right.$ or t-test) \\
\hline $\begin{array}{l}\text { Factor V Leiden heterozygous mutation } \\
\text { Factor V Leiden homozygous mutation }\end{array}$ & $30(68.1)$ & $50(80.6)$ & 0.05 \\
Prothrombin G20210A heterozygous & $6(12.8)$ & $2(3.0)$ & 0.06 \\
$\begin{array}{l}\text { mutation } \\
\text { Protein C, S deficiency }\end{array}$ & $8(17.0)$ & $15(24.2)$ & 0.36 \\
Antithrombin deficiency & $2(4.3)$ & $1(1.6)$ & 0.58 \\
Lupus anticoagulans antibodies & $2(4.3)$ & 0 & 0.19 \\
More than one trombophilic state & $2(4.3)$ & 0 & 0.19 \\
\end{tabular}

Data are expressed as $\mathrm{n}(\%)$.

Table 2. Clinical characteristics of patients with thrombophilias.

\begin{tabular}{|c|c|c|c|}
\hline & $\begin{array}{l}\text { History of venous } \\
\text { thromboembolism } \\
\mathrm{n}=47\end{array}$ & $\begin{array}{l}\text { No history of venous } \\
\text { thromboembolism } \\
n=62\end{array}$ & $\begin{array}{l}\text { p } \\
\left(\chi^{2} \text { or t-test }\right)\end{array}$ \\
\hline Age, years (mean $\pm S D)$ & $42.9 \pm 13.0$ & $40.3 \pm 12.9$ & 0.80 \\
\hline Male sex & $22(46.8)$ & $21(33.9)$ & 0.17 \\
\hline History of cardiovascular disease & $2(4.2)$ & $2(3.2)$ & 1.0 \\
\hline History of diabetes/impaired fasting glucose & $0(0)$ & $2(3.2)$ & 0.51 \\
\hline Ever smoker & $17(36.2)$ & $24(38.7)$ & 0.92 \\
\hline Hypolipidemic treatment & $5(10.6)$ & $7(11.3)$ & 0.91 \\
\hline Antihypertensive treatment & $12(25.5)$ & $5(8.1)$ & 0.013 \\
\hline Hormonal therapy (\%) & $4(8.5)$ & $8(12.9)$ & 0.68 \\
\hline Body height, cm, (mean $\pm S D)$ & $174.9 \pm 9.2$ & $173.9 \pm 9.7$ & 0.61 \\
\hline Body weight, $\mathrm{kg},($ mean $\pm S D)$ & $81.6 \pm 18.0$ & $74.6 \pm 16.3$ & 0.04 \\
\hline Waist circumference, $\mathrm{cm},($ mean $\pm S D)$ & $89.3 \pm 15.0$ & $84.1 \pm 13.6$ & 0.06 \\
\hline Hip circumference, $\mathrm{cm},($ mean $\pm S D)$ & $103 \pm 10.3$ & $100 \pm 9.1$ & 0.12 \\
\hline Body mass index $\mathrm{kg} / \mathrm{m}^{2},($ mean $\pm S D)$ & $26.5 \pm 5.0$ & $24.4 \pm 3.7$ & 0.04 \\
\hline Systolic blood pressure, $\mathrm{mmHg}$, (mean $\pm S D)$ & $119.1 \pm 14.1$ & $119.8 \pm 16.6$ & 0.84 \\
\hline Diastolic blood pressure, $\mathrm{mmHg},($ mean $\pm S D)$ & $73.8 \pm 10.2$ & $73.3 \pm 9.5$ & 0.78 \\
\hline Pulse rate, $n / \mathrm{min},($ mean $\pm S D)$ & $69.4 \pm 7.8$ & $69.7 \pm 7.6$ & 0.81 \\
\hline Intima-media thickness, $m m($ mean $\pm S D)$ & $0.577 \pm 0.170$ & $0.558 \pm 0.123$ & 0.07 \\
\hline
\end{tabular}

Data are expressed as n (\%) if not stated differently.

In detailed analysis, Belcaro score I both in carotid and femoral artery was found in $31.9 \%(n=15)$ patients with a history of VTE and in $40.3 \%(n=25)$ patients without history of VTE. Belcaro score II in carotid or femoral artery was found in $23.4 \%(n=11)$ patients with a history of VTE and in $9.7 \% \quad(n=6)$ patients without the history of VTE. Finally, Belcaro score III in carotid or femoral artery was found in $23.4 \%$ $(n=11)$ patients with a history of VTE and in $25.9 \%$ $(n=16)$ patients without history of VTE. These distributions were not significantly different between groups under the study.

The intima media thickness in the VTE group was higher than in non-VTE group $(0.577 \pm 0.170 \mathrm{~mm}$ vs. 
Table 3. Preclinical atherosclerosis expressed as Belcaro score more than Class I and associated intima-media thickness values in patients with thrombophilias.

$\begin{array}{ll}\begin{array}{l}\text { History of venous } \\ \text { thromboembolism }\end{array} & \begin{array}{l}\text { No history of venous } \\ \text { thromboembolism }\end{array}\end{array} \quad$ p ( $\chi^{2}$ or t-test $)$

\begin{tabular}{|c|c|c|c|}
\hline All patients & $\mathrm{n}=47$ & $n=62$ & \\
\hline Belcaro score more than $I^{*}, n(\%)$ & $32(68.1)$ & $37(59.7)$ & 0.37 \\
\hline$I M T, m m($ mean $\pm S D)$ & $0.613 \pm 0.189$ & $0.592 \pm 0.141$ & 0.17 \\
\hline $\begin{array}{l}\text { Patients with BMI less than } \\
30 \mathrm{~kg} / \mathrm{m}^{2}\end{array}$ & $\mathbf{n}=\mathbf{3 3}$ & $\mathbf{n}=\mathbf{5 9}$ & \\
\hline Belcaro score more than $I^{*}, n(\%)$ & $23(69.7)$ & $34(57.6)$ & 0.25 \\
\hline$I M T, m m($ mean $\pm S D)$ & $0.586 \pm 0.181$ & $0.586 \pm 0.135$ & 0.97 \\
\hline Patients with BMI less than & & & \\
\hline $\begin{array}{l}30 \mathrm{~kg} / \mathrm{m}^{2} \text { and no antihypertensive } \\
\text { therapy }\end{array}$ & $\mathbf{n}=\mathbf{3 1}$ & $\mathbf{n}=\mathbf{5 5}$ & \\
\hline Belcaro score more than $I^{*}, n(\%)$ & $21(67.7)$ & $30(54.5)$ & 0.23 \\
\hline$I M T, m m($ mean $\pm S D)$ & $0.568 \pm 0.097$ & $0.574 \pm 0.132$ & 0.59 \\
\hline
\end{tabular}

*Defined as the highest value found in the arterial system (carotid or femoral). IMT, intima media thickness; BMI, body mass index.

Table 4. Intima media thickness (IMT) and preclinical atherosclerosis expressed as Belcaro score more than Class I in patients with factor V Leiden mutation.

\begin{tabular}{llll}
\hline & $\begin{array}{l}\text { History of venous } \\
\text { thromboembolism } \\
\mathbf{n = 3 6}\end{array}$ & $\begin{array}{l}\text { No history of venous } \\
\text { thromboembolism } \\
\mathbf{n}=\mathbf{5 2}\end{array}$ & $\mathbf{p}\left(\chi^{\mathbf{2}}\right.$ or t-test) \\
\hline $\begin{array}{l}\text { IMT, } m \text { m (mean } \pm S D) \\
\text { Belcaro score more than } I^{*}, n(\%)\end{array}$ & $\begin{array}{l}0.574 \pm 0.179 \\
25(69.4)\end{array}$ & $\begin{array}{l}0.560 \pm 0.109 \\
32(61.5)\end{array}$ & 0.20 \\
\hline
\end{tabular}

*Defined as the highest value found in the arterial system (carotid or femoral).

$0.558 \pm 0.123 \mathrm{~mm}$, but this difference was of borderline significance $(\mathrm{p}=0.07)$ (Table 2$)$.

The results in a subgroup of patients with factor $\mathrm{V}$ Leiden mutation did not differ from those of the whole study population (Table 4).

\section{Discussion}

In this study, hypertension and overweight were strongly associated with the history of VTE in patients with thrombophilias. Nevertheless, preclinical atherosclerosis expressed as Belcaro score or intima media thickness in carotid and femoral arteries were not found to be strongly associated with the history of VTE.

Hypertension is accompanied with prothrombotic state (Remková and Remko 2009) and it is considered to be one of possible contributors to the risk of VTE, but in different studies different results were reported. While in some studies (Hong et al. 2005) hypertension was significantly associated with VTE of unknown origin, this association was not confirmed by others (Tsai et al. 2002, Glynn and Rosner 2005). We found more prevalent antihypertensive treatment in patients with a history of VTE and this finding might be also associated with their higher body mass index.

Our study has been done in a younger population than are populations generally described in the literature. Therefore, obesity and hypertension as potential predecessors of atherosclerosis were associated with VTE, but not preclinical atherosclerosis measured by ultrasound. This observation is supported by other findings in older population (Prandoni et al. 2003, Hong et al. 2005). In these studies the mean age of the patients with VTE was 67 and 61 years; in contrast to the mean 
age of the patients in our study which was 43 years. An additional, to our opinion more important difference is that these studies recruited more participants from general population compared to our study, in which only patients with thrombophilias were recruited. Therefore, our study indicates that life style modification focused on cardiovascular risk factors - based on our data mainly on the weight reduction and blood pressure - might not only prevent atherosclerotic complications but also thromboembolic events.

More than $50 \%$ of VTE cases in our study were secondary thromboses. Therefore, the lack of the association between preclinical atherosclerosis and VTE may also be explained by a higher proportion of secondary causes in our VTE cohort compared to other studies published so far. In two published studies (Bilora et al. 2003, Prandoni et al. 2003) secondary thromboses were not associated with more prevalent atherosclerosis. In our study, $40.4 \%$ of VTE cases were unprovoked, while the others were secondary thromboses attributable to immobilization and hormonal use.

The strength of the study is the focus on patients with well defined thrombophilias, who have not been studied so far. The limited size of the study population and the absence of control group of age-matched subjects without thrombophilias is a certain draw-back of our study. Other limitation might represent a somewhat asymmetric distribution of the subjects with factor $\mathrm{V}$ Leiden mutations, because particularly homozygous mutation is known to be a stronger risk factor for VTE than heterozygous mutation. Nevertheless, the study results did not change after the exclusion of the subjects with a homogenous mutation of factor V Leiden. Large, prospective and because of relative low number of patients with particular thrombophilias, multi-centre studies should be performed to improve the risk stratification of patients with thrombophilias and to definitely confirm the absence/presence of an association between preclinical atherosclerosis and venous thromboembolism.

In conclusion, we found that obesity and hypertension are strongly associated with a history of venous thromboembolism in patients with thrombophilias. We did not find strong association between preclinical atherosclerosis and venous thromboembolism in this group of patients.

\section{Conflict of Interest}

There is no conflict of interest.

\section{Acknowledgements}

This study was supported by the grant of the Czech Ministry of Health No. NR/9396-3/2007.

\section{References}

AGENO W, PRANDONI P, ROMUALDI E, GHIRARDUZZI A, DENTALI F, PESAVENTO R, CROWTHER M, VENCO A: The metabolic syndrome and the risk of venous thrombosis: a case-control study. $J$ Thromb Haemost 4: 1914-1918, 2006.

AGENO W, BECATTINI C, BRIGHTON T, SELBY R, KAMPHUISEN PW: Cardiovascular risk factors and venous thromboembolism: a meta-analysis. Circulation 117: 93-102, 2008.

BANK I, LIBOUREL EJ, MIDDELDORP S, VAN PAMPUS ECM, KOOPMAN MM, HAMULYAK K, PRINS MH, VAN DER MEER J, BÜLLER HR: Prothrombin 20210A mutation: a mild risk factor for venous thromboembolism but not for arterial thrombotic disease and pregnancy-related complications in a family study. Arch Intern Med 164: 1932-1937, 2004.

BECATTINI C, AGNELLI G, PRANDONI P, SILINGARDI M, SALVI R, TALIANI MR, POGGIO R, IMBERTI D, AGENO W, POGLIANI E, PORRO F, CASAZZA F: A prospective study on cardiovascular events after acute pulmonary embolism. Eur Heart J 26: 77-83, 2005.

BELCARO G, NICOLAIDES AN, LAURORA G, CESARONE MR, DE SANCTIS M, INCANDELA L, BARSOTTI A: Ultrasound morphology classification of the arterial wall and cardiovascular events in a 6-year follow-up study. Arterioscler Thromb Vasc Biol 16: 851-856, 1996.

BILORA F, BOCCIOLETTI V, PETROBELLI F, GIROLAMI A: Atherosclerosis and secondary deep vein thrombosis: a difficult correlation. Clin Appl Thromb Hemost 9: 121-124, 2003. 
BOVA C, MARCHIORI A, NOTO A, ROSSI V, DANIELE F, SANTORO C, RICCHIO R, DE LORENZO R, UMBACA R, PRANDONI P: Incidence of arterial cardiovascular events in patients with idiopathic venous thromboembolism. A retrospective cohort study. Thromb Haemost 96: 132-136, 2006.

CROWTHER MA, KELTON JG: Congenital thrombophilic states associated with venous thrombosis: a qualitative overview and proposed classification system. Ann Intern Med 138: 128-134, 2003.

EITZMAN DT, WESTRICK RJ, SHEN Y, BODARY PF, GU S, MANNING SL, DOBIES SL, GINSBURG D: Homozygosity for factor V Leiden leads to enhanced thrombosis and atherosclerosis in mice. Circulation 111: 1822-1825, 2005.

GILLUM RF: Pulmonary embolism and thrombophlebitis in the United States, 1970 - 1985. Am Heart J 114: 12621264, 1987.

GLYNN RJ, ROSNER B: Comparison of risk factors for the competing risks of coronary heart disease, stroke, and venous thromboembolism. Am J Epidemiol 162: 975-982, 2005.

GLYNN RJ, DANIELSON E, FONSECA FA, GENEST J, GOTTO AM Jr, KASTELEIN JJ, KOENIG W, LIBBY P, LORENZATTI AJ, MACFADYEN JG, NORDESTGAARD BG, SHEPHERD J, WILLERSON JT, RIDKER PM: A randomized trial of rosuvastatin in the prevention of venous thromboembolism. $N$ Engl J Med 360: 1851-1861, 2009.

HONG C, ZHU F, DU D, PILGRAM TK, SICARD GA, BAE KT: Coronary artery calcification and risk factors for atherosclerosis in patients with venous thromboembolism. Atherosclerosis 183: 169-174, 2005.

LIJFERING WM, COPPENS M, VAN DE POEL MH, MIDDELDORP S, HAMULYÁK K, BANK I, VEEGER NJ, PRINS MH, BÜLLER HR, VAN DER MEER J: The risk of venous and arterial thrombosis in hyperhomocysteinaemia is low and mainly depends on concomitant thrombophilic defects. Thromb Haemost 98: 457-463, 2007.

LOWE GD: Common risk factors for both arterial and venous thrombosis. Br J Haematol 140: 488-495, 2008.

MAHMOODI BK, BROUWER JL, VEEGER NJ, VAN DER MEER J: Hereditary deficiency of protein C or protein S confers increased risk of arterial thromboembolic events at a young age: results from a large family cohort study. Circulation 118: 1659-1667, 2008.

MARCHIORI A, MOSENA L, PRINS MH, PRANDONI P: The risk of recurrent venous thromboembolism among heterozygous carriers of factor V Leiden or prothrombin G20210A mutation. A systematic review of prospective studies. Haematologica 92: 1107-1114, 2007.

MIGLIACCI R, BECATTINI C, PESAVENTO R, DAVI G, VEDOVATI MC, GUGLIELMINI G, FALCINELLI E, CIABATTONI G, DALLA VALLE F, PRANDONI P, AGNELLI G, GRESELE P: Endothelial dysfunction in patients with spontaneous venous thromboembolism. Haematologica 92: 812-818, 2007.

NORDSTRÖM M, LINDBLAD B, BERGQVIST D, KJELLSTRÖM T: A prospective study of the incidence of deepvein thrombosis within a defined urban population. J Intern Med 232: 155-160, 1992.

PRANDONI P: Links between arterial and venous disease. J Intern Med 262: 341-350, 2007.

PRANDONI P, BILORA F, MARCHIORI A, BERNARDI E, PETROBELLI F, LENSING AW, PRINS MH, GIROLAMI A: An association between atherosclerosis and venous thrombosis. $N$ Engl J Med 348: 1435-1441, 2003.

REICH LM, FOLSOM AR, KEY NS, BOLAND LL, HECKBERT SR, ROSAMOND WD, CUSHMAN M: Prospective study of subclinical atherosclerosis as a risk factor for venous thromboembolism. $J$ Thromb Haemost 4: 1909-1913, 2006.

REMKOVÁ A, REMKO M: The role of renin-angiotensin system in prothrombotic state in essential hypertension. Physiol Res 59: 13-23, 2010.

ROSENDAAL FR, SISCOVICK DS, SCHWARTZ SM, BEVERLY RK, PSATY BM, LONGSTRETH WT Jr, RAGHUNATHAN TE, KOEPSELL TD, REITSMA PH: Factor V Leiden (resistance to activated protein C) increases the risk of myocardial infarction in young women. Blood 89: 2817-2821, 1997.

SØRENSEN HT, HORVATH-PUHO E, PEDERSEN L, BARON JA, PRANDONI P: Venous thromboembolism and subsequent hospitalisation due to acute arterial cardiovascular events: a 20-year cohort study. Lancet 370: 1773-1779, 2007. 
TSAI AW, CUSHMAN M, ROSAMOND WD, HECKBERT SR, POLAK JF, FOLSOM AR: Cardiovascular risk factors and venous thromboembolism incidence: the longitudinal investigation of thromboembolism etiology. Arch Intern Med 162: 1182-1189, 2002.

VAN DER HAGEN PB, FOLSOM AR, JENNY NS, HECKBERT SR, O'MEARA ES, REICH LM, ROSENDAAL FR, CUSHMAN M: Subclinical atherosclerosis and the risk of future venous thrombosis in the Cardiovascular Health Study. J Thromb Haemost 4: 1903-1908, 2006. 